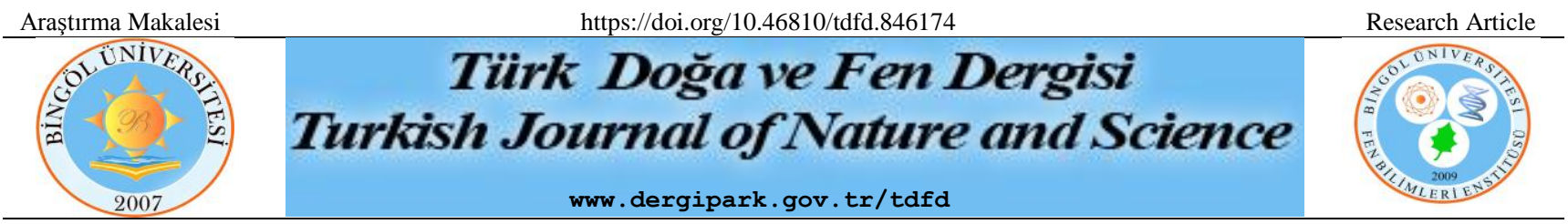

\title{
Makine Öğrenmesi Yöntemleri Kullanılarak Elektrikli Cihazların Sınıflandırılması
}

\author{
Feyyaz KOÇ ${ }^{1 *}$, Abdulkerim KARABIBBER ${ }^{1}$ \\ ${ }^{1}$ Bingöl Üniversitesi, Mühendislik ve Mimarlık Fakültesi, Elektrik - Elektronik Mühendisliği Bölümü, Bingöl, Türkiye \\ Feyyaz KOÇ ORCID No: 0000-0002-1024-7889
}

Abulkerim KARABIBBER ORCID No: 0000-0003-0244-4425

*Sorumlu yazar:fkoc@bingol.edu.tr

(Alınış: 24.12.2020, Kabul: 29.03.2021, Online Yayınlanma: 25.06.2021)

\begin{abstract}
Anahtar
Kelimeler

Makine

öğrenmesi,

Siniflandirma,

Elektrikli ev

aletleri,

Destek vektör

makineleri

Öz: Elektrik enerjisinin daha verimli bir şekilde kullanılabilmesi güç sistemlerinin takip ve analizi ile mümkündür. Üretim ve tüketim tarafında yer alan sistem bileşenlerinin doğru tanımlanması durumunda, güç sistemlerinin karakteristik davranışları ve muhtemel tepkileri belirlenebilmektedir. Ayrıca, yük atma ve yük kaydırma gibi güç kontrol uygulamalarında elektrikli aletlerin yük modellerine göre sınıflandırılması gerekmektedir. Bu çalışmada, tüketim tarafında yer alan elektrikli cihazlar aktif ve reaktif güç tüketimleri referans alınarak sınıflandırılmaktadır. Örnek elektrikli cihaz olarak evlerde ve ofislerde sıkça kullanılan 5 adet farklı tüketim karakteristiğine sahip cihaz seçilmiştir. Sınıflandırma için son zamanlarda yaygın olarak kullanılan makine öğrenmesi algoritmalarından destek vektör makinaları, kolektif öğrenme ve karar ağaçları seçilip karşılaştırılmış ve bu sınıflandırıcıların yapılarından en iyi sonuçları veren beş algoritmanın performansı analiz edilmiştir. Elde edilen sonuçlara göre \% $\% 3,4$ ile en yüksek doğruluk oranını ve 50,285 saniye ile en kısa eğitim süresinde veren yöntem destek vektör makineleri olmuştur.
\end{abstract}

\section{Classification of Electrical Appliances Using by Machine Learning Methods}

Keywords
Machine
learning,
Classification,
Electrical
equipment,
Support
vector
machines

\begin{abstract}
More efficient use of electrical energy is possible with the monitoring and analysis of power systems. In the case system components on the production and consumption side are defined correctly, the characteristic behavior and possible responses of the power systems can be determined. In addition, electrical devices should be classified according to load models for power control applications such as load shedding and load shifting. In this study, electrical devices on the consumption side are classified based on their active and reactive power consumption. Five electrical devices with different consumption characteristics, which are frequently used in homes and offices, have been selected for the experiments. For the classification of devices, support vector machines, ensemble learning and decision trees, which are among the machine learning algorithms used recently, were selected and compared, and the performance of the five algorithms that gave the best results from the structures of these classifiers were analyzed. According to the results, support vector machines were the method that gave the highest accuracy rate with $83.4 \%$ and the shortest training time with 50.285 seconds.
\end{abstract}

\section{GİRIŞ}

Ülkelerin kalkınma, refah ve gelişimlerini sağlamada birincil derecede önemli olan enerji, teknoloji ile birlikte hayatın birçok alanında temel ihtiyaç haline gelmiştir. Enerji tedarikinde yenilenebilir ve fosil ürünü kaynaklar kullanılmaktadır. Dünya genelinde enerjinin büyük bir kısmı fosil yakıtlara dayalı petrolden karşılanmaktadır. Petrol ürünleri çevreye zararlı, tükenebilir ve birçok ülke için pahalı enerji kaynaklarıdır. Petrol rezervlerinin azalmasıyla birlikte enerji maliyetleri daha da yükselmeye başlamıştır [1]. Enerji tedarikinde diğer bir kaynak olan yenilenebilir enerji kaynaklarının en önemli avantajları çevre dostu, her yerde bulunabilir ve tükenmez olmalarıdır. Ancak ilk yatırım maliyetinin fazla olması ve üretimlerinin kesintili olması nedeniyle yenilenebilir enerji kaynaklarının kullanımı kısıtlı kalmaktadır. Yenilenebilir ve petrol türevi enerji kaynaklarının sahip olduğu bu olumsuzluklar ve artan enerji talebi göz önüne alındığında, enerjinin daha verimli kullanılması gerektiği görülmektedir. 
Enerjinin daha etkin ve verimli kullanılması hususunda farklı çözüm önerileri sunulmaktadır. Bu önerilerden bir tanesi elektrikli cihazların, enerjinin ucuz olduğu saatlerde kullanılmasını sağlayana zaman tabanlı enerji yönetimidir [2]. Bu ve benzeri enerji yönetim sistemleri için elektrikli cihazların karakteristik özelliklerine göre sınıflandırılması gerekmektedir. Cihazların sınıflandırılmasındaki en önemli nokta tüketim esnasında akım, gerilim, güç ve güç faktörü gibi imza niteliğinde olan özelliklerin tanımlanmasıdır [3]. Referans [4] ve [5]'te hane halkının tercih edilen sıcaklığa göre, ortamın sicaklığını otomatik olarak ayarlayan 1sitma/soğutma sistemlerinin enerji tüketimini azaltacağ1 gösterilmektedir. Enerji tasarrufu sağlamaya yönelik bir diğer çalışma, faaliyet tabanlı maliyet sistemidir. Bu sistemin amacı, işletme koşulları altında cihazların maliyetini ve enerji giderlerini belirlemektir [6]. Evleri bir bütün olarak düşünerek binaların enerji yönetim sistemine geliştirmeye yönelik çalışmalar da vardır. Örneğin enerji tasarruflu zincir yönetimi, binalar için enerji tasarrufu performansını en üst düzeye çıkarmayı hedefleyen etkili bir yöntem olmuştur [7]. Ayrıca yapılan araştırmalar evsel tesislerin enerji yönetiminde bilinçlendirme yardımları ile toplam olarak \%20 enerji tasarrufu sağladığını göstermektedir [8].

Enerjinin verimli kullanılması ve üretiminde çevreye verdiği zararın önlenmesi her bir bireyin bu konuda bilinçlenmesi ve sorumluluk alması ile mümkündür. $\mathrm{Bu}$ kapsamda, enerji yönetiminin evden başlaması gerektiği düşünülerek konut enerji yönetim sistemi geliştirilmiştir [9]. İlgili çalışmada kontrol otomasyonu, optimize edilmiş insan benzeri kararlar önermek için yapay sinir ağları ve destek vektör makinesi kullanılarak gerçekleştirilmiştir. Kamu binalarında enerji verimliliği konusunu ele almak adına enerji tüketimini tahmin etmek için makine öğrenimi modelleri olușturulmuştur [10]. Bu çalışmalarda, akıllı şehir kavramının bir parçası olarak kamu binaları için makine öğrenimi tabanlı enerji yönetimi mimarileri önerilmektedir. Solar güç sistemleri, artan enerji ihtiyacını karşılamak için güvenilir, ucuz ve çevre dostu bir alternatiftir. Solar santrallerin tesis ediliş yerinin seçimi için fizibilite çalışmalarının yapılması ve sistemlerin elde edilen analiz sonuçlarına göre tasarlanması, yapılacak yatırımların maliyet/fayda oranının belirlenmesi açısından önemli bir adım olmaktadır. Kurulması planlanan solar santrallerin üretim kapasitesini tahmin etmek makine öğrenmesi modelleri ile mümkündür [11]. Bu amaç doğrultusunda, solar sistemler için güneş 1şınımı tahmin etmek için yapay sinir ağları, çoklu doğrusal regresyon ve en yakın komşu regresyon yöntemleri kullanılmış ve tatmin edici sonuçlar elde edilmiştir.

$\mathrm{Bu}$ çalışmada, elektrikli aletler makine öğrenmesi yöntemleri kullanılarak sinıflandırmaktadır. Elektrikli alet olarak ofislerde ve evlerde sıklıkla kullanılan beş adet elektrikli cihaz seçilmiştir. Bu aletlerin aktif ve reaktif güç tüketim değerleri ile akım ve gerilim armonikleri ölçülmüş ve öznitelikleri çıkarılmıştır. Öznitelik çıkarmak için bir boyutlu yerel ikili örüntü operatörü ile aritmetik ortalama, standart sapma ve ortanca değer fonksiyonları kullanılmıştır. Seçilen cihazların sınıflandırılmasında makine öğrenmesi algoritmalarından destek vektör makinaları, karar ağaçları ve kolektif öğrenme yöntemleri kullanılmıştır. Elde edilen sonuçlara göre destek vektör makinalarının iki yapısı olan doğrusal destek vektör makineleri ve kuadratik destek vektör makineleri; sınıflandırıcı toplulukların yapılarından olan ağaç topluluğu ve altuzay diskiriminant ve karar ağaçlarının yapılarından olan iyi ağaç yöntemleri en iyi sonuçları veren sınıflandırıcılar olmuştur.

\section{MODEL GELİ̧TIRME VE ÖZELLİK SEÇIMI}

\section{1. Özellik Çıarma ve Seçimi}

Yirmi birinci yüzyıl, bilginin hızlı geliştiği bir çağdır. Bu çağda veri miktarında büyük artışlar olmuştur. Büyük hacimli verilerin içinden yararlı bilginin çıkarılması veri madenciliğinin görevidir [12]. $\mathrm{Bu}$ işlem, bir veri tabanındaki büyük miktarda veriden gizli, önceden bilinmeyen ve potansiyel olarak değerli bilgileri ortaya çıkarma sürecidir [13-15]. Veri madenciliğinde en önemli aşamalardan biri veri boyutunun küçültülmesidir. Veri boyutunun küçültülmesi ilgisiz verilerin çıkarılmasını ve işlem yükünün azalmasını sağlar [16]. Özellik seçimi, veri kapsamını küçültmek için kullanılan metotlardan biridir. Özellik seçimi gerçekleştirmenin asıl maksadı, sinyallerin alakalı veya eşsiz özelliklerini ortaya çıkarmaktır. Bu özellikler daha sonra ilgili verilerin en doğru şekilde sınıflandırılması için kullanılır. Başka bir deyişle, özellik seçimi, orijinal veri kümesini temsil edebilecek en iyi alt kümenin seçimi olarak tanımlanır veya tüm veri kümesini en doğru sekilde tanımlamak için gereken veri miktarını basitleştirir veya en aza indirir [17]. Bu çalışmada, beş adet cihazdan alınan veri setini sınıflandırmak için yapılan özellik çıkarımında; aritmetik ortalama, standart sapma, ortanca değer ve bir boyutlu yerel ikili örüntü tekniği kullanılmıştır.

Bilinmeyen bir örüntünün sınıflandırılması üç kategoriye dayanmaktadır. Bunlar, istatistiksel, deterministik ve bulanık küme teorisi ilkeleridir. İstatistiksel özellik metodu, verileri minimize etmek ve cihazlardan elde edilen anlık aktif ve reaktif güç verilerinden özellikler çıkarmak için kullanılır.

Sinyal; $\mathrm{x}_{1}, \mathrm{x}_{2}, \ldots$ ve $\mathrm{x}_{\mathrm{n}}$ olan birçok veri içerdiğinden, veriler aşağıdaki istatistiksel özelliklerin üçüne indirgenir.

Özellik 1: Aritmetik ortalama, bir sayı dizisindeki sayıların toplamının dizideki eleman sayısına bölünmesi ile elde edilen değerdir.

$$
\text { Aritmetik Ortalama }=X_{a}=\frac{\sum_{i=1}^{n} X_{i}}{N}
$$

Özellik 2: Standart sapma, analiz edilen verilerin ortalamasını belirledikten sonra varyansın karekökü alınarak elde edilen değerler dizinidir. Standart sapma, her bir veri noktasının ortalamaya göre sapmas1 belirlenerek varyansın karekökü olarak hesaplanır [11]. 
Elde edilen veriler ortalama değerden uzak ise sapma değeri yüksek çıkar. Diğer bir ifadeyle, veriler birbirinden ne kadar uzak ise standart sapma o kadar yüksek olur.

Standart sapma $(s t d)=\sqrt{s^{2}}=\sqrt{\frac{\sum_{i-1}^{n}\left(x_{i}-\bar{x}\right)^{2}}{n-1}}$

Özellik 3: Ortanca değer (Medyan), bir sayısal veri serisi siralandığında ortada kalan sayıdır.

Tek sayıda veri $=\left\{x_{1}, x_{2}, x_{3}, x_{4}, x_{5}, x_{6}, x_{7}, x_{8}, x_{9}\right\}$

$$
\text { Çift sayıda veri }=\left\{\begin{array}{c}
\left\{x_{1}, x_{2}, x_{3}, \boldsymbol{x}_{\mathbf{4}}, \boldsymbol{x}_{\mathbf{5}}, x_{6}, x_{7}, x_{8}\right\} \\
\downarrow \\
\frac{\boldsymbol{x}_{\mathbf{4}}+\boldsymbol{x}_{\mathbf{5}}}{2}
\end{array}\right.
$$

\subsection{Yerel İkili Örüntï}

Görüntü işleme uygulamaları için etkili ve üretken yöntemlerden biri Yerel İkili Örüntü (YİÖ) yöntemidir. YİÖ kullanılarak, yerel olarak tekrar eden kalıplar ortaya çıkarılır. YİÖ genel olarak 3x3 piksel görüntülere uygulanır. YIÖ'de, $3 \times 3$ piksel görüntülerin merkez değeri, komşu sekiz piksele göre yeniden kodlanır. YİÖ yönteminin açıklayıcı bir görsel örneği Şekil 1'de gösterilmektedir [18]. YİÖ kodlaması yapıldığında, gri seviye değerleri dikkate alınır. Merkezi piksel değeri ilk piksel (sol üst) değerle karşılaştırılır. Merkezi piksel değeri ilk piksel değerinden büyükse, 1 olarak kodlanır, aksi takdirde 0 olarak kodlanır. Bu, diğer komşu pikseller için de gerçekleştirilir. İkili sayı, sol üstteki pikselden başlayarak kodlanır ve Şekil 1'de gösterilen yönde ilerledikten sonra 8 bitlik bir ikili sayı elde edilir. Orta pikselin yeni değeri, elde edilen 8-bit ikili sayının ondalık eşdeğeridir [19].

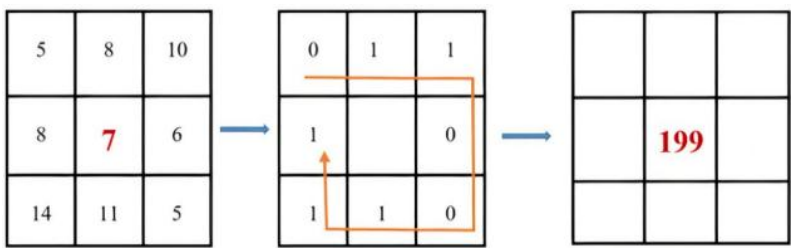

Şekil 1. 3×3 Piksel görüntü için yerel ikili örüntü kodlaması

\subsection{Bir Boyutlu Yerel İkili Örüntü}

3x3 YİÖ'den bir boyutlu YİÖ dönüştürme işleminde, 3x3 piksel görüntü yerine dokuz örnek-uzunluklu pencere yapıs1 dikkate alınır. Bu pencere yapısı Şekil 2'de gösterilmektedir. $\mathrm{P}_{\mathrm{i}}$, penceredeki i. örneği temsil eder ve $\mathrm{P}_{\mathrm{c}}$, merkezi örnek olarak isimlendirilen beşinci örneği temsil eder. Bir boyutlu YïÖ yönteminin temel matematiksel ifadesi Eşitlik 5'te gösterildiği gibidir.

$$
P_{c}=\sum_{i=1}^{N} \mathrm{f}(x) 2^{i-1}
$$

Burada $\mathrm{f}(x)$ işaret fonksiyonu olup şu şekilde ifade edilir:

$$
f(x)= \begin{cases}0, & P_{i}<P_{c} \\ 1, & P_{i} \geq P_{c}\end{cases}
$$

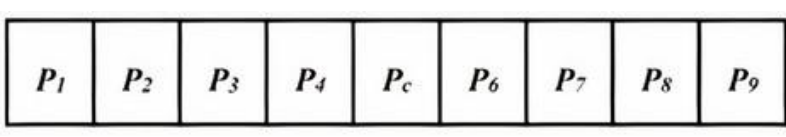

Şekil 2. Bir boyutlu yerel ikili örüntü pencere yapısı

Örnek bir uygulama olarak Şekil 3(a) ve (b)'de gösterilen $\mathrm{x}(\mathrm{x}=15,17,21,30,39,41,40,37,36)$ gibi bir sinyal ele alınmıştır. Bir boyutlu YİÖ'de, Şekil 3 (c) 'de gösterildiği gibi, en soldaki komşudan $\left(\mathrm{P}_{1}\right)$ başlayarak ve komşu dizileri merkezi örnekle karşılaştırarak 8 bitlik bir ikili dizi elde edilir. Merkezi numune değeri, 8-bit ikili sayının Eșitlik (4) kullanılarak ondalık sayıya dönüştürülmesiyle elde edilir (Şekil 3(d)). Bir boyutlu YİÖ işlemi, pencerenin tüm sinyal boyunca kaydırılmasıyla gerçekleştirilir [20].

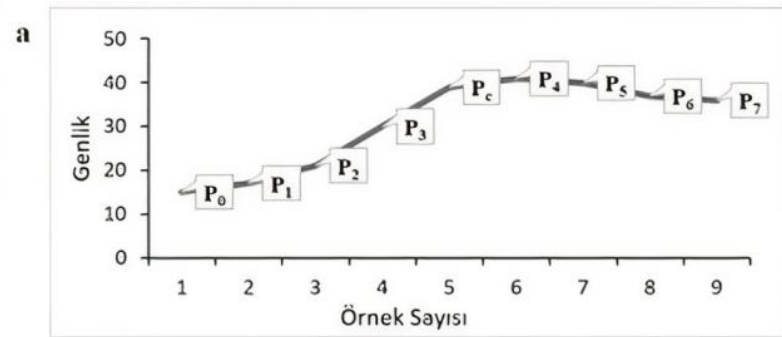

\begin{tabular}{|l|l|l|l|l|l|l|l|l|}
\hline $\mathbf{P}_{0}$ & $\mathbf{P}_{1}$ & $\mathbf{P}_{2}$ & $\mathbf{P}_{3}$ & $\mathbf{P}_{\mathrm{c}}$ & $\mathbf{P}_{4}$ & $\mathbf{P}_{5}$ & $\mathbf{P}_{6}$ & $\mathbf{P}_{7}$ \\
\hline 15 & 17 & 21 & 30 & 39 & 41 & 40 & 37 & 36 \\
\hline
\end{tabular}

\begin{tabular}{|c|c|c|c|c|c|c|c|c|}
\hline $\mathbf{P}_{\mathbf{0}}$ & $\mathbf{P}_{1}$ & $\mathbf{P}_{\mathbf{2}}$ & $\mathbf{P}_{3}$ & $\mathbf{P}_{\mathrm{C}}$ & $\mathbf{P}_{4}$ & $\mathbf{P}_{5}$ & $\mathbf{P}_{6}$ & $\mathbf{P}_{7}$ \\
\hline $\mathbf{0}$ & $\mathbf{0}$ & $\mathbf{0}$ & $\mathbf{0}$ & & $\mathbf{1}$ & $\mathbf{1}$ & $\mathbf{0}$ & $\mathbf{0}$ \\
\hline
\end{tabular}

\begin{tabular}{|l|l|l|l|l|l|l|l|l|}
\hline $\mathbf{P}_{0}$ & $\mathbf{P}_{1}$ & $\mathbf{P}_{2}$ & $\mathbf{P}_{3}$ & $\mathbf{P}_{\mathbf{c}}$ & $\mathbf{P}_{4}$ & $\mathbf{P}_{5}$ & $\mathbf{P}_{6}$ & $\mathbf{P}_{7}$ \\
\hline & & & & $\mathbf{1 2}$ & & & & \\
\hline
\end{tabular}

Şekil 3. Örnek bir sinyal için bir boyutlu YïÖ kodlaması

\section{SINIFLANDIRMA ALGORITMALARI}

Makina öğrenimi günümüzün en çok üzerinde durulan kavramlarından biridir. Bilgisayar algoritmalarının genel adı olan bu kavram, belirlenmiş bir problemi kendisine ait ortamdan elde edilen verileri kullanarak modeller. $\mathrm{Bu}$ alanda oldukça fazla çalışmanın varlığından dolayı önerilen birçok yaklaşım ve algoritma mevcuttur. Probleme yaklaşımlarına göre farklılık gösterebilen makina öğrenimi yöntemleri, farklı problemlerde farklı başarılara sahip olabilirler.

Sınıflandırmada hiç bilinmeyen bir örneğe mantıklı cevap verilmesi amaçlanır. Bunun için de sınıflandırıcılar önceden eğitilir. Veri sayısı sınırlı olur. $\mathrm{Bu}$ sınırlı verilerin bir kısmı eğitimde bir kısmı da sistemin başarısının test edilmesinde kullanılır. $\mathrm{Bu}$ ölçümün başarısının tarafsız bir şekilde olması gerekir. 
Bunun için çapraz geçerlik ismiyle bilinen metotlar kullanılmaktadır. Çapraz geçerlilik ya da k-kat çapraz geçerlilik, veri kümesinin rastgele ' $\mathrm{k}$ ' tane gruba bölünmesi işlemidir. $\mathrm{Bu}$ gruplardan biri test için kullanılırken kalanlar eğitim için kullanılır. Daha sonra başka bir grup eğitimde kalanlar testte kullanılır. Bu şekilde işlem tekrarlanır ve böylece her grup hem eğitilmiş hem de testte kullanılmış olacaktır. Her grubun eğitilmiş olması modelin doğruluğunu artırmaktadır. Örneğin, şekil 4'te hayali bir model için çapraz geçerlilik katı 5 olarak belirlenmiştir. Yani veri kümesi 5 gruba ayrılmış ve model $5 \mathrm{kez}$ eğitilip test edilmiştir. Böylece her grup hem test seti hem de eğitim seti olarak kullanılmıştır.

\begin{tabular}{|l|l|l|l|l|l|}
\hline Bölme 1 & Kat 1 & Kat 2 & Kat 3 & Kat 4 & Kat 5 \\
\hline Bölme 2 & Kat 1 & Kat 2 & Kat 3 & Kat 4 & Kat 5 \\
\hline Bölme 3 & Kat 1 & Kat 2 & Kat 3 & Kat 4 & Kat 5 \\
\hline Bölme 4 & Kat 1 & Kat 2 & Kat 3 & Kat 4 & Kat 5 \\
\hline Bölme 5 & Kat 1 & Kat 2 & Kat 3 & Kat 4 & Kat 5 \\
\hline \multicolumn{7}{|c|}{ Test Verisi } & Eğitim Verisi \\
\hline
\end{tabular}

Şekil 4. Çapraz geçerliliği 5 olarak alınan model

Makina öğrenimi alanında sınıflandırma problemlerini çözmeye yönelik çeşitli algoritmalar geliştirilmiştir. Bunlardan biri olan Destek Vektör Makineleri, örüntü tanıma ve sınıflandırma problemlerinin çözümü için Vapnik tarafından geliştirilmiştir [21]. Destek Vektör Makineleri (DVM) 1970'lerin sonlarında sunulmuş, istatistiksel öğrenme teorisine dayalı öğrenme algoritmalarıyla birlikte yaygin olarak kullanılan bir denetimli öğrenme modelidir [22]. Küçük örneklem, doğrusal olmayan ve yüksek boyutlu örüntü tanıma problemlerini çözmede birçok benzersiz avantaj gösterir [23-24]. Ek olarak, sağlam bir teorik temele ve basit ve anlaşılır matematiksel modellere sahiptir. $\mathrm{Bu}$ nedenle DVM, yüz tanıma, zaman serisi tahmini ve örüntü tanıma gibi birçok problemde yaygın olarak kullanılmaktadır [25-27]. Son yıllarda, DVM giderek daha fazla ilgi görmüş; bilgisayar bilimi, yenilenebilir enerji alanı, istatistik ve veri madenciliğinde çok kullanılan bir yöntem olmuştur [28].

Doğrusal DVM, doğrusal bir destek vektör makinesi tasarlamak için bir kesme düzlemi algoritmasının özgün bir tescilli sürümünü uygulayan algoritmadır. Doğrusal DVM ultra büyük veri kümelerinden, çok sınıflı sınıflandırma problemlerini çözmek için en yeni ve son derece hızlı makine öğrenimi yöntemidir. Doğrusal DVM, doğrusal olarak ölçeklenebilir bir yordamdır, yani eğitim veri kümesinin boyutuyla doğrusal olarak ölçeklenen bir zamanda bir DVM modeli oluşturur.
Bilinen diğer DVM modelleriyle karşılaştırmalarımız, yüksek doğruluk gerektiğinde üstün performansını açıkça göstermektedir. $\mathrm{Bu}$ çalışmada, yapılan sınıflandırmada en yüksek oranı doğrusal DVM sınıflandırıcısı vermiștir.

\section{ELEKTRİKLI EV ALETLERININ SINIFLANDIRILMASI}

$\mathrm{Bu}$ çalışmada ofislerde sıkça kullanılan elektrikli aletlerin güç tüketimleri sınıflandırılmaktadır. Örnek cihaz olarak vantilatör, elektrikli çaydanlık, laptop, monitör ve yazıcı seçilmiştir. Deneylerde her bir cihazdan farklı sürelerde 15 adet ölçüm alınmıştır. Ölçüm aleti olarak Hioki PW3198 güç analizörü kullanılmıştır. Öznitelik çıkarımında 465 özellik bir boyutlu yerel ikili örüntü operatörü, 465 özellik standart sapma fonksiyonu, 465 özellik ortanca değer fonksiyonu ve 465 özellik aritmetik ortalama fonksiyonu kullanılarak toplam 1860 adet özellik sinıflandırmada kullanılmıştır. Özniteliklerin sınıflandırılmasına yönelik yapılan deneysel çalışmalarda çapraz geçerlilik yöntemi uygulanmıştır. Çapraz geçerlilik katmanı 10 olarak belirlenmiştir. Ölçüm alınan cihazların aktif güç tüketimleri Şekil 5(a)'da gösterilmektedir. Vantilatör tek kademede çalıştırıldığı için sabit güç çekmekte ve çektiği anlık güç yaklaşık olarak 34 Watt olmaktadır. Aynı şekilde monitör ve elektrikli çaydanlığın yükleri sabit olduğundan çektikleri aktif güçte sabit ve sırasıyla $18 \mathrm{~W}$ ve $1450 \mathrm{~W}$ olmaktadır. Yazıcının bekleme ve çalışma esnalarında güç tüketimi farklıdır ve $0 \mathrm{~W}$ ile 900 W arasında değişmektedir. Benzer şekilde dizüstü bilgisayarın, kullanılan program ve donanıma bağlı olarak güç tüketimi $25 \mathrm{~W}$ ile $56 \mathrm{~W}$ arasında değişmektedir. Şekil 5(b)'de aynı cihazların reaktif güç tüketimleri gösterilmektedir. Elektronik donanımı fazla olan cihazlarda reaktif güç tüketimi yüksek ve değişkendir. Bunun sebebi elektronik cihazlarda kullanılan yarı iletken anahtarlama elemanlarının harmonik üretmesi ve reaktif güç gereksinimidir. Manuel kontrole sahip elektrikli çaydanlık ve vantilatörde reaktif güç tüketimleri sabit ve azdır.
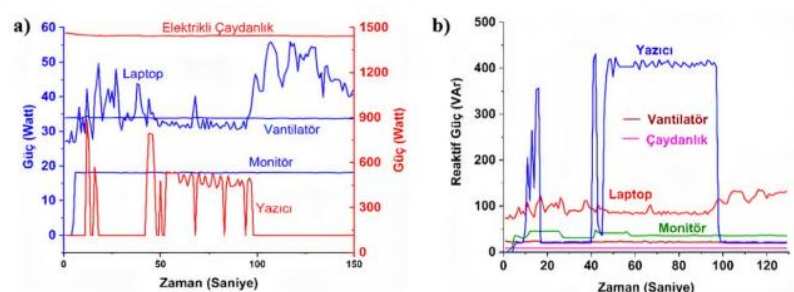

Şekil 5. Ölçümleri alınan cihazların, a) aktif ve b) reaktif güç tüketimleri

Veri seti olușturmak amacıyla bes cihazın ayrı ayrı ve birlikte çalışma varyasyonları göz önünde bulundurularak toplam 465 ölçüm alınmıştır. $\mathrm{Bu}$ ölçümler, MATLAB programı veri çizme özelliği kullanılarak görselleştirilmiştir. Örnek olarak, Şekil 6'da aynı anda beş cihazın çalışması durumunda elde edilen aktif ve reaktif güç tüketimi gösterilmektedir. Yüz elli saniyelik güç tüketimini gösteren sinyaller anlık olarak değişkenlik göstermektedir. Bu değişkenliğin sebebi dizüstü bilgisayar ve yazıcının güç tüketimlerinin sabit 
olmamasıdır. Her cihazın kendine özgü bir güç tüketme karakteristiği vardır. Örneğin yazıcıda aktif güç tüketiminde ani değişimler gözlenirken; ayaklı vantilatörde güç tüketimi sabittir. Bunun gibi ayırt edici karakteristik özellikler, elektrikli cihazlara ait 'güç imzası' ile kavramsallaştırılır. Güç imzalarından alınan bilgiler kullanılarak elektrikli cihazlar sinıflandırılmaktadır.

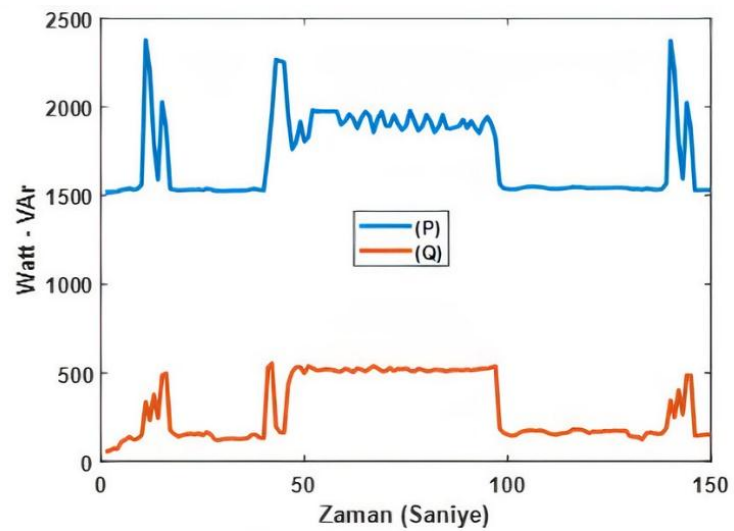

Şekil 6. Bütün cihazların aynı anda çalışması durumunda toplam aktif ve reaktif güç tüketimleri

Elektrikli cihazlara ait öznitelikler standart sapma, ortanca değer ve aritmetik ortalama gibi fonksiyonlar ve bir boyutlu yerel ikili örüntü (1B-YİÖ) tekniği ile çıkarıldı. Bu özniteliklerden faydalanılarak MATLAB programinda bulunan sınıflama ara yüzü (classification learner) kullanılarak cihazlar sınıflandırıldı. Sınıflama uygulaması, verileri sınıflandırmak için modelleri eğitir. Model eğitimi verilerin işlenmesi, özelliklerin belirlenmesi ve doğrulama şemalarının oluşturulması ile yapılır. MATLAB programında hazır ara yüz olarak 24 adet sınıflandırıcı bulunmaktadır. Karar ağaçları, ayırt edici analiz, destek vektör makineleri, lojistik regresyon, en yakın komşular, Naive Bayes ve topluluk sınıflandırması dahil olmak üzere en iyi sınıflandırma modeli türünü aramak için otomatik eğitimler gerçekleştirilebilmektedir.

Şekil 7(a)'da doğrusal Destek Vektör Makinası tekniğine dayalı tahmin modelinin doğru sonuçları gösterilmektedir. Dizüstü bilgisayar ' $\mathrm{l}$ ', vantilatör 'f', elektrikli çaydanlık ' $k$ ', yazıcı ' $p$ ' ve monitör ' $m$ ' ile gösterilmektedir. Bunların ikili, üçlü, dörtlü ve beşli kombinasyonu, bu harflerin yan yana yazılması ile sembolize edilmiștir. Örneğin; 'fp' vantilatör ile yazıcının aynı anda çalışması durumunda oluşan sınıfı temsil etmektedir. Ayrıca her renk bir sınıfı temsil etmektedir. İlgili rengin ait olduğu sınıf şekilde belirtilmiştir. Doğru tahmin edilen veriler dairelerle gösterilirken yanlış veriler çarpı işareti ile gösterilmektedir. $\mathrm{Bu}$ modelde 465 veriden 388 tanesi doğru 77 tanesi yanlış tahmin edilerek doğruluk oranı $\% 83,4$ olmuştur. 'p' 'f', 'fk' gibi bazı sınıflara ait veriler tam doğru tahmin edilmiştir. Diğer taraftan bazı sınıflara ait hem doğru hem de yanlış tahminler bulunmaktadır. Yapılan bütün yanlış tahminler Şekil 7 (b)'de gösterilmektedir. Yanlış tahminlere bakıldığında 19 sınıfa ait veriler görülmektedir. Şekil 8'de doğrusal destek vektör makinası sınıflandırıcısına ait karmaşıklık matrisi verilmiștir. Karmașıklık matrisinde, sinyallerin ait oldukları gerçek sınıflar ile doğrusal destek vektör makinası sinıflandırıcısına ait tahmin edilen sinıflar verilmiştir. 31 sınıfa ait sinyallerin ait oldukları sınıflarda ne oranda doğru veya yanlış tahmin edildiğini gösteren yeşil ve bej renkleridir. Yeşilin veya bejin tonları ise ilgili sınıfın ne oranda doğru veya yanlış tahmin edildiğini göstermektedir. Örneğin 'f' sınıfına ait sinyallerin tamamı doğru tahmin edildiği için ilgili bölme koyu yeşil olurken, 'fkm' sınıfına ait veriler en az doğru tahmin edilen sınıflardan biri olduğundan ilgili bölme açık yeşil olmuştur.

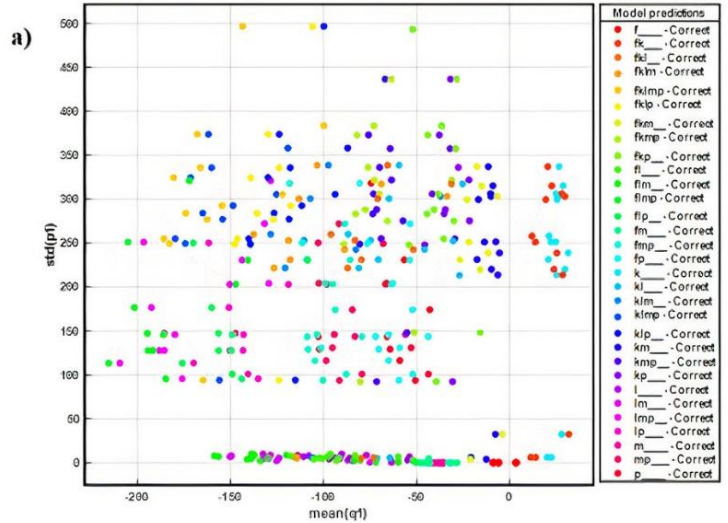

b)

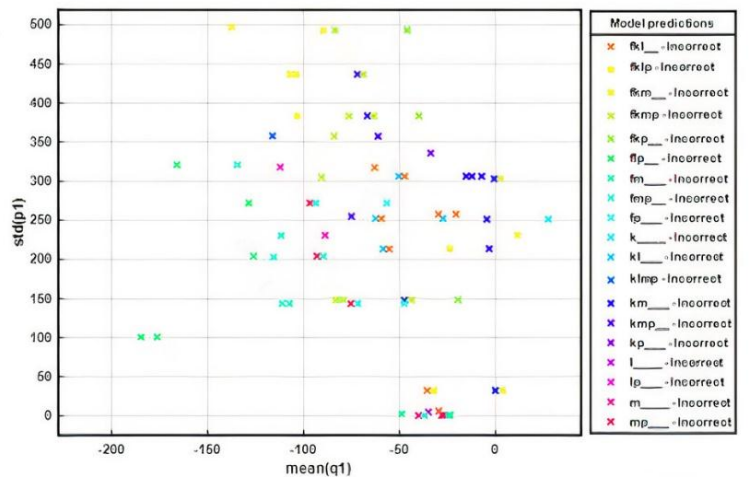

Şekil 7. Doğru ve yanlış tahmin edilen sınıflar

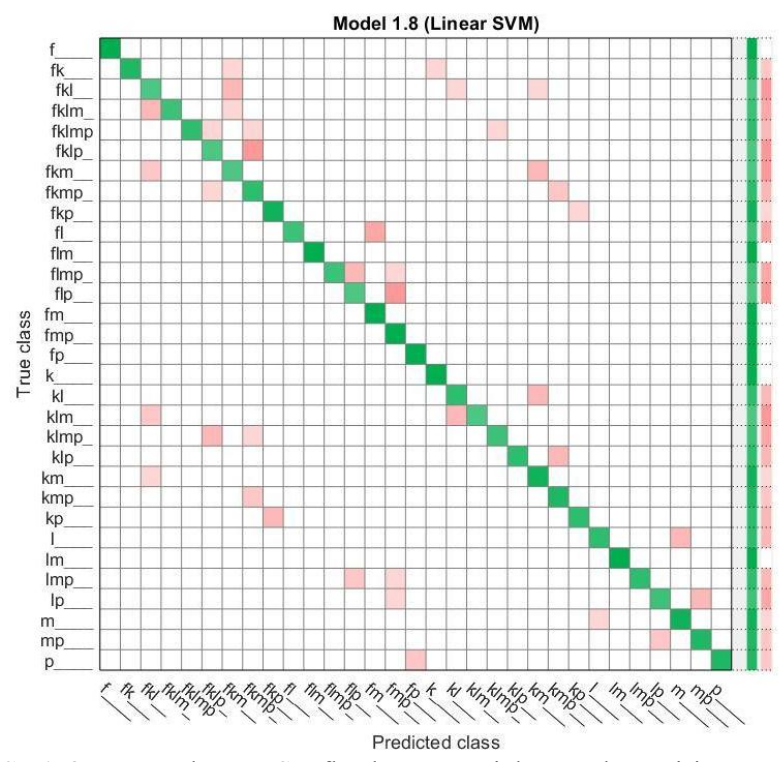

Şekil 8. Doğrusal DVM Sınıflandırmasına ait karmaşık matrisi 
MATLAB programında yaygın bir şekilde kullanılan yöntemler ile yapılan sınıflandırmada en yüksek doğruluk oranına sahip 5 sınıflandırıcı Tablo 1'de verilmiştir. Tabloda sınıflandırıcıların doğruluk oranları, eğitim süreleri, tahmini hız değerleri verilmiştir. Tabloda; doğrusal DVM, Ağaç Topluluğu, Altuzay Diskiriminant, Kuadratik DVM ve İyi Ağaç sınıflandırıcılarına ait doğruluk oranları sırası ile $\% 83,4$, $\% 82,8, \% 82,8, \% 82,2$ ve \%81,5 olarak ortaya çıkmıştır. Eğitim süresi, işlem yükünün azlığını ve programın etkinliğini gösteren parametre olduğundan kısa olması arzu edilir. Tabloya baktığımızda, doğruluk oranı en yüksek doğrusal DVM iken en düşük İyi Ağaç olmuştur. Eğitim süreleri bakımından en hızlı olan 2,0946 saniyelik süre ile İyi Ağaç olmuştur. Altuzay Diskiriminant 186,81 saniyelik eğitim süresi ile en uzun süreye sahip olmuştur. En yüksek doğruluk oranına sahip olan Doğrusal DVM'de eğitim süresi 50,285 saniye olmuştur.

Çapraz doğrulama veya "k-kat çapraz doğrulama", veri kümesinin gelişigüzel "k" gruplarına ayrılması işlemidir. $\mathrm{Bu}$ gruplardan biri test seti olarak kullanılır ve geri kalanı eğitim seti olarak kullanılır. Böylece model her grup ile bu şekilde tekrarlı olarak eğitilir ve kalan diğer grup ile test edilir. Bu metotla tüm verileri kullanılarak ilgili model eğitilmiş olacaktır. $\mathrm{Bu}$ eğitim, modelin tahmin başarısını belirlemede önemli bir rol oynamaktadır. Bu çalışmada, çapraz geçerlilik katı 10 olarak belirlenmiştir. Yani veriler 10 gruba ayrılmış ve modeller 10 defa eğitilip test edilmiştir. Tablo 2'de çapraz geçerlilik katının sabit ve sinyal sürelerinin farklı olması durumunda en yüksek doğruluk oranlarını veren sınıflandırıcılar gösterilmektedir. Sinyal süresi 20 saniye olması durumunda \%69,2 doğruluk oranıyla en yüksek değeri Ağaç Topluluğu modeli vermiştir. Sinyal süresi 45 oluncaya kadar sınıflandırıcılarda doğru tahmin etme artmıștır. Örneğin, sinyal süresi 30 saniyelik iken oran \%75,9 (Ăgaç Topluluğu) ve sinyal süresi 40 saniye olduğunda oran \%80,2 (İyi Ağaç) olmuştur. Sinyal süresi 45 olduğunda ise en yüksek oran olan \%83,9 (Doğrusal DVM) elde edilmiştir. Sinyal süresinin 45 saniyenin üstüne çıkması durumunda sınıflandırıcıların doğru tahmin oranı nispeten azalmaktadır. 50 saniyelik sinyal süresinde en yüksek doğruluk oranı \%82,6 ile Doğrusal DVM olmuştur. 60 ve 70 saniyelik sinyal sürelerinde ise en yüksek doğruluk oranları \%79,6 (Ağaç Topluluğu) ve \%78,1 (Ağaç Topluluğu) olarak gerçekleşmiştir. Bu sonuçlar sinyal süresine bağlı olarak sınıflandırıcı modellerinin doğruluk oranının değiştiğini ve en iyi doğruluk oranın 45 saniyede alındığını göstermektedir.

Tablo 1. En iyi sonucu veren beş sınıflandırıcıya ait sonuçlar

\begin{tabular}{|l|l|l|l|}
\hline Sinıflandırıcılar & $\begin{array}{l}\text { Doğruluk } \\
(\%)\end{array}$ & $\begin{array}{l}\text { Eğitim } \\
\text { Süresi } \\
(\text { san. })\end{array}$ & $\begin{array}{l}\text { Tahmin Hızı } \\
(1 / \text { san.) }\end{array}$ \\
\hline Doğrusal DVM & 83,4 & 50,285 & 200 \\
\hline Ağaç Topluluğu & 82,8 & 179,94 & 550 \\
\hline Altuzay Diskiriminant & 82,8 & 186,81 & 430 \\
\hline Kuadratik DVM & 82,2 & 93,625 & 100 \\
\hline İyi Ağaç & 81,5 & 2,0946 & 6700 \\
\hline
\end{tabular}

Tablo 2. En yüksek doğruluk oranını veren sinıflandırıcılar

Tablo 2. En yüksek doğruluk oranını veren sınıflandırıcılar
\begin{tabular}{|c|c|c|c|}
\hline $\begin{array}{c}\text { Sinyal } \\
\text { Süresi } \\
\text { (Saniye) }\end{array}$ & $\begin{array}{c}\text { Çapraz } \\
\text { Geçerlilik }\end{array}$ & $\begin{array}{c}\text { Doğruluk } \\
(\%)\end{array}$ & Sınıflandırıcı \\
\hline 20 & 10 & 69,2 & Ağaç Topluluğu \\
\hline 30 & 10 & 75,9 & Ağaç Topluluğu \\
\hline 40 & 10 & 80,2 & İyi Ağaç \\
\hline 45 & 10 & 83,9 & Doğrusal DVM \\
\hline 50 & 10 & 82,6 & Doğrusal DVM \\
\hline 60 & 10 & 79,6 & Ağaç Topluluğu \\
\hline 70 & 10 & 78,1 & Ağaç Topluluğu \\
\hline
\end{tabular}

Sınıflandırma işleminin tam doğru olması için, verilerin net özelliklerle birbirlerinden ayrılması gerekir. Bu durum pek mümkün olmadığı için genellikle doğruluk oranı \%100 çıkmaz. Bu çalışmada yanlış çıkan veri sayıs1 77 olmuştur. Şekil 7(b)'de gösterilen bu veriler incelendiğinde, 'f' ve ' $\mathrm{k}$ ' ile sembolize edilen vantilatör ve elektrikli çaydanlığın içinde bulunduğu veriler çoğunluktadır. Şekil 5(a) incelendiğinde, vantilatör ve laptop güç tüketim değerlerinin birbirlerine oldukça yakın olduğu görülmektedir. Bu durum, bu iki sinyalden çıkarılan özniteliklerin benzer çıkmasına ve yanlış sinıflandırmaya sebep olmaktadır. Şekil 5(b) incelendiğinde ise elektrikli çaydanlık, vantilatör ve monitör sinyalleri birbirlerine yakındır. Aynı şekilde bu durum da öznitelik çıkarmada benzerliğe sebep olacağından, yanlış tahminlere neden olmaktadır.

\section{SONUÇ}

$\mathrm{Bu}$ çalışmada, ofis aletlerini güç tüketimlerine göre sınıflandırmada sezgisel yöntemlerin performansları karşılaştırılmıştır. Örnek cihaz olarak elektrikli çaydanlık, vantilatör, yazıcı, dizüstü bilgisayar ve monitör kullanılmış ve bu cihazlarından farklı varyasyonlarda ölçümler alınmıștır. Ölçüm verileri MATLAB programında sıkça kullanılan başlıca yöntemler ile sınıflandırılmıştır. Sinıflandırmalarda belirleyici özellik olarak aktif ve reaktif güçler ile gerilim ve akım armonikleri kullanılmıștır. En yüksek doğrululuk oranını elde etmek için beş farklı tip sınıflandırıcı karşılaştırılmıştır. Sinıflandırıcıların doğruluk oranları eğitim için kullanılan sinyallerin süresine bağlı olarak farklılık gösterdiği gözlemlenmiştir. En yüksek oranın \%83,9 ile Doğrusal Destek Vektörü yöntemine ait olduğu belirlenmiştir. Bu oran, 465 adet ölçümden elde edilmiş olup 388'nin doğru olarak tahmin edildiği anlamına gelmektedir. Yanlış verilerin genellikle çoklu cihaz kullanımlarında meydana geldiği görülmüştür. Gelecek çalışmada, cihazların aktif güç tüketimlerine göre alt sınıflara ayrılması ve bu sayede başarı oranının artırılması hedeflenmektedir.

\section{Teşekkür}

Çalışmamızda yardımlarından dolayı Ömer Faruk ALÇİN ve Hüseyin ÜZEN'e teşekkür ederiz. 


\section{KAYNAKLAR}

[1] Aydın Ü, Peker H, Gönülalan UA. 7. Petrol Sektörü. In: Türkiye'nin Enerji Görünümü. 2000. p. 161-214.

[2] Hung Y, Michailidis G. Modeling and Optimization of Time-of-Use Electricity Pricing Systems. IEEE Transactions on Smart Grid. 2019; 10(4): 4116-4127.

[3] Weiss M, Staake T, Guinard D, Roediger W. eMeter: An interactive energy monitor. In: UbiComp. 2009. p. 3-4.

[4] Neenan B, Robinson J, Boisvert RN. Residential electricity use feedback: a research synthesis and economic framework. Electric Power Research Institute (EPRI), 2009.

[5] Abeykoon V, Kankanamdurage N, Senevirathna A, Ranaweera PS, Udawapola R. Real Time Identification of Electrical Devices through Power Consumption Pattern Detection. 2016 First International Conference on Micro and Nano Technologies Modelling and Simulation, March 2016. Kuala Lumpur, Malaysia.p.1-3. doi:10.1109/MNTMSim.2016.13.

[6] Kavrar Ö, Yılmaz B. Enerji Yönetiminde Faaliyet Tabanlı Maliyetleme Modeli: Bir Üretim İşletmesinde Uygulama. Muhasebe ve Finansman Dergisi. 2019; (83): 85-110.

[7] Jing-xiao Z, Hui L, Li B. Life cycle influence mechanism of energy-saving chain management on energy-saving building construction. 2010 International Conference on Mechanic Automation and Control Engineering, Wuhan, 2010.p.1904-7. doi:10.1109/MACE.2010.5536595

[8] D'Alessandro S, Tonello AM, Monacchi A, Elmenreich W. Home energy management systems: Design guidelines for the communication infrastructure. In: ENERGYCON 2014 - IEEE International Energy Conference. IEEE; 2014. p. 805-12.

[9] Krishna Prakash N, Prasanna Vadana D. Machine Learning Based Residential Energy Management System. In: 2017 IEEE International Conference on Computational Intelligence and Computing Research, ICCIC 2017. IEEE; 2018.

[10] Zekić-Sušac M, Mitrović S, Has A. Machine learning based system for managing energy efficiency of public sector as an approach towards smart cities. International Journal of Information Management [Internet]. 2020; (March 2019):102074. Available from: https://doi.org/10.1016/j.ijinfomgt.2020.10207.

[11] UĞUZ S, ÇAĞLAYAN N, ORAL O. PV Güç Santrallerinden Elde Edilecek Enerjinin Makine Öğrenmesi Metotları Kullanılarak Tahmin Edilmesi. Uluslararası Mühendislik Araştırma ve Geliştirme Derg [Internet]. 2019;11(3):769-79. Available from: http://dx.doi.org/10.29137/umagd.514933.

[12] Wu X, Zhu X, Wu GQ, Ding W. Data mining with big data. IEEE Transactions On Knowledge And Data Engıneerıng. 2014;26(1):97-107. doi: 10.1109/TKDE.2013.109.
[13] Lin M, Wang H, Xu Z, Yao Z, Huang J. Clustering algorithms based on correlation coefficients for probabilistic linguistic term sets. International Journal of Intelligent Systems. 2018;33(12):240224.

[14] Rygielski C, Wang JC, Yen DC. Data mining techniques for customer relationship management. Technology in Society.2002; 24(4):483-502.

[15] Wang XZ, He Q, Chen DG, Yeung D. A genetic algorithm for solving the inverse problem of support vector machines. Neurocomputing. 2005;68(1-4):225-38.

[16] BUDAK H. Özellik Seçim Yöntemleri ve Yeni Bir Yaklaşım. Süleyman Demirel Üniversitesi Fen Bilim Enstitüsü Derg. 2018;22(Özel):21-31.

[17] Ladha L, Deepa T. Feature Selection Methods And Algorithms. Int J Comput Sci Eng. 2011;3(5):1787-97.

[18] Güner A, Alçin ÖF, Şengür A. Automatic digital modulation classification using extreme learning machine with local binary pattern histogram features. Meas J Int Meas Confed. 2019;145:21425.

[19] Huang D, Shan C, Ardabilian M, Wang Y, Chen L. Local binary patterns and its application to facial image analysis: A survey. IEEE Trans Syst Man Cybern Part C Appl Rev. 2011;41(6):765-81.

[20] Huang D, Shan C, Ardabilian M, Wang Y, Chen L. Local binary patterns and its application to facial image analysis: A survey. IEEE Trans Syst Man Cybern Part C Appl Rev. 2011;41(6):765-81.

[21] Cortes C, Vapnik V. Support-vector networks. Mach Learn. 1995;20:273-97. https://doi.org/10.1007/BF00994018.

[22] Huang S, Aydin M, Lipo TA. TORUS concept machines: Pre-prototyping design assessment for two major topologies. Conf Rec - IAS Annu Meet (IEEE Ind Appl Soc. 2001;3(August):1619-25.

[23] Yang L, Xu Z. Feature extraction by PCA and diagnosis of breast tumors using SVM with DEbased parameter tuning. Int J Mach Learn Cybern. 2019;10(3):591-601.

[24] Zhang J, Hou Q, Zhen L, Jing L. Locality similarity and dissimilarity preserving support vector machine. Int $\mathrm{J}$ Mach Learn Cybern. 2018;9(10):1663-74.

[25] Chen SG, Wu XJ. A new fuzzy twin support vector machine for pattern classification. Int J Mach Learn Cybern. 2018;9(9):1553-64.

[26] Wang XZ, Lu SX, Zhai JH. Fast fuzzy multicategory SVM based on support vector domain description. Int $\mathrm{J}$ Pattern Recognit Artif Intell. 2008;22(01):109-20.

[27] Üzen H, Hanbay K. Yaya Özellik Tanıma için LM Filtre Temelli Derin Evrişimsel Sinir Ağ Polytech. 2019;0900(3):605-13.

[28] Karabiber A, Alçin ÖF. Short Term PV Power Estimation by means of Extreme Learning Machine and Support Vector Machine. 7th International Istanbul Smart Grids and Cities Congress and Fair, ICSG 2019 - Proceedings. 2019. p. 41-4. 